\title{
Implications on Domestic Non-Profit Organizations of Japanese Home Care Service
}

\author{
Guihua Liu, Yiying Yang \\ School of Public Management and Politics and Law, Southwest Jiaotong University, Chengdu, China \\ Email: ktflower@126.com, 18200289082@163.com
}

How to cite this paper: Liu, G.H. and Yang, Y.Y. (2017) Implications on Domestic Non-Profit Organizations of Japanese Home Care Service. Open Access Library Journal, 4: e3663.

https://doi.org/10.4236/oalib.1103663

Received: May 10, 2017

Accepted: June 6, 2017

Published: June 9, 2017

Copyright $\odot 2017$ by authors and Open Access Library Inc.

This work is licensed under the Creative Commons Attribution International License (CC BY 4.0).

http://creativecommons.org/licenses/by/4.0/

\section{(c) (i) Open Access}

\begin{abstract}
China's aging problem is continuing to ferment, so that the state is advocating the non-profit organizations to actively provide home care services. However, China's non-profit organizations lack of the prophets in home care service, so they need to learn a lot from foreign advanced experience. Japan, which is a neighbor of our country, has been rich in old service experience because of its early entry into the aging country of Asia. Therefore, the main content of this paper is the implications of Japanese home care service to our nonprofit organization. After analyzing the present situation of non-profit organization's participation in home-based old-age service and the experience of non-profit organization in Japan, this paper analyzes the obstruction and deficiency of non-profit organization's participation in home care service. On the basis of the previous analysis, the author further explores the implications of Japan's experience of old service to China's non-profit organization's participation in home care, with a view to China's non-profit organizations in the future to provide home care services to provide reference.
\end{abstract}

\section{Subject Areas}

Sociology

\section{Keywords}

Japan, Service for the Old, Non-Profit Organizations, Home Care Service

\section{Introduction}

The increasing trend of population aging in our country has brought great impact to the sustainable development of social old-age security system. Followed by the negative impact of aging, such as "reduced demographic dividend", it increased social security services and increased family pension burden. In order to solve these negative effects and improve our old service system, since the 80's last 
century, our country has started to explore and try the old-age service of the urban community. And in recent years, our country learned from the developed countries to introduce the non-profit organizations to participate in home care service.

Although it has made some achievements and formed a certain scale, many relevant issues about home care service like limited scope for the old, single and repeat service items and contents, insufficient supply of funds and limited financial resources, lack of professional staff, insufficient number of volunteers who are unevenly distributed and lack of comprehensive training, not perfect policies and regulations about home care service, lack of close cooperation and communications between families and communities as well as communities and non-profit organizations are still remained resolved now. Our non-profit organizations enter a period of vigorous development and show an upward trend now. Wherein, some non-profit organizations participate in the community home care service; they all fail to achieve the desired effect. Japan, a neighboring country to us, has entered the aging society in the late seventies which advanced nearly thirty years than our country. As a result, Japan has a more perfect home care service system and relevant experience. They rely on the strength of non-profit organizations and use "Care Insurance System" to provide a full range of home care service for the old [1].

Therefore, aiming to provide a reference for non-profit organizations to provide higher quality and more comprehensive home care services for the elderly in the future, and helping to alleviate and improve the negative impact of aging, this paper draws lessons from Japan's merits and achievements in mobilizing the power of non-profit organizations, and sums up the revelation of Japan's old service experience to China's non-profit organization's participation in home care.

\section{The Relationship between Non-Profit Organizations and Home Care Service}

\subsection{Non-Profit Organizations and Home Care Service}

Western countries put forward the concept of "home care service" for the first time and we defined this concept in "Opinions on Promoting the Work of Home Care Service" as: a form that provides both life and spiritual services for the old who are living at home, and this should base on government and social forces and rely on the communities. In other words, it refers to a kind of specialized home care service which takes families as the core and relies on the communities. Non-profit organizations participate in home care service and aim at taking part in home care service and management in diversified forms through legal means [2]. As represented by Japan, home care service refers to the organic combination of family pension and social pension, and it is a social pension model which extends community pension to family [3].

\subsection{Non-Profit Organization Is One of the Important Home Care Participants}

As Savas [4] said, there are three basic participants in public service: consumers, producers and service providers. And if we specific to home care service, the 
three main participants are government, service providers which are mainly non-profit organizations and the older age group who accept the services. Government purchases dominate in home care service that non-profit organizations participate in, while government purchases originated in Britain "Community Care". It refers that the government entrusts part of the public services it assumes direct responsibility before to these qualified social organizations, later relevant departments will evaluate the services they provide after completion, and finally, the government pays a certain fee according to their assessments. This is a new pattern that the government provides public services for the people and we can summarize it as "Government Commitment, Directional Delegation, Contract Management and Assessment Honor" [5]. In addition, the specific mechanism of home care service mainly includes government support, nonprofit organizations provide services and the old enjoy services. All these show that as the service provider, non-profit organizations are the backbone of community home care service system [1].

\section{Experience That Non-Profit Organizations Participate in Japanese Home Care Service}

Japanese municipal government establishes a special social department which is fully responsible for all the works about home care service. What's more, the social department is further refined as welfare planning section, social welfare section, the elderly welfare section, insurance and medical section as well as home for the old, etc. It masters the health status, economic status, daily activities and many other materials of the old within the whole city. Under the support of relevant policies and regulations, both community and non-profit organizations fully cooperate, gather the strength of all parties to provide different comprehensive and high quality services for the old according to their demands. Such home care service that the community and non-profit organizations participate in joint not only enriches the life of older people, but also reduces the burden for young people [6].

Take the Japanese "Ling Board" as example, main methods this non-profit organization participates in the elderly care activities include: home nursing service, organizing small-scaled service day in elderly activity centers and providing care assistance services for the old. All these three methods give full play to the power of non-profit organizations, and the volunteers often visit the old and those with limited mobility in the community, they promote mutual exchange and give them moral support and comfort through conducting leisure activities. In order to ensure the meticulous assistance services that the old who are compliance with "care insurance" can enjoy, non-profit organizations often communicate with the old and their families who have nursing demand, and then develop a reasonable care plan through the liaison of assistance agencies.

\subsection{Perfect Legal System Protects the Home Care Service of Non-Profit Organizations}

Japanese home care service bases on national legislation and depending on con- 
tinuous enhancement and completeness of relevant laws, its development has become more perfect. In addition, this sound legal also ensures the smooth implementation of pension system. Japanese welfare system is no longer available only to the low-income elderly population who stay below the poverty line, and now it becomes a social welfare system that basically covers all the people.

There are three relevant laws about elderly welfare in Japan: "Elderly Welfare Law", "Elderly Health Law" and "Care Insurance Law", and these laws witness the three development stages of home care service provided by Japanese society. In addition, Japanese government promulgated "10-year Strategy to Promote Elderly Person Health Welfare (1990-1999)" in 1989 for its strategic development; then it made a comprehensive revision in 1994 and formed "New Promote Strategic to Promote Elderly Person Health Welfare (1995-1999)". Later in order to enable older persons to acquire various home care services as well as reduce the burden of home care, the government enriched access nursing, facilities nursing, day care and other home care services as well as the contents of home health care service, and then developed "10-year Strategy to Promote Elderly Person Health Welfare". These three strategies are called "Gold Plan", "New Gold Plan" and "Gold Plan in the $21^{\text {st }}$ Century" [7]. Followed by "Nursing Insurance Law", "Promotion Law of Specified Nonprofit Activities (NPO)" was introduced in 1998. When simplifying the registration as well as expanding activity areas of non-profit organizations, "NPO Law" also strengthened social supervision and management to non-profit organizations. In addition, this law also promoted the further development of nonprofit organizations in Japan and enabled it to play a more important role in home care service. "Care Insurance System" issued in 2000 not only solved the burden of elderly care, but also mobilized social forces and promoted the formation of complete home care system in Japan [8]. All these policies and regulations mentioned above provide relevant legal guarantee for non-profit organizations to participate in home care service system.

\subsection{The Implementation of Nursing Care Insurance System Ensures the Participation of Non-Profit Organizations in Home Care Service}

Many contents mentioned above are all related to the nursing care insurance system. The so-called system means that because of the increasingly prominent of Japanese aging issue in the late 1990s, the number of elderly people who need home care service increases drastically. As a result, Japan converted its longterm care system into social insurance system to meet the needs of the times, and began to implement this care insurance system in April, 2000 [9]. Japanese government separated pension from medical insurance and developed home care service into the main form of pension. Meanwhile, Japanese government also actively opened up the pension market and more private capital was permitted. Once the policy was introduced, the whole pension industry in Japanese society began to introduce new and the elderly nursing specialty also achieved rapid development. Apart from these, this policy also indirectly improved the 
academic education level as well as professional and technical literacy of the staff who engaged in elderly nursing career [10]. While also because of the implementation of this system, Japanese non-profit organizations could participate in home care service more smoothly. What's more, they might also provide professional home service, day services, short-term service, long-term service and various forms of service more pertinently for the old [11].

In addition, Japanese government also made a clear distinction between those non-profit organizations providing services for the elderly and other types of organizations, and it divided nursing care insurance into three different facilities: nursing facility of elderly welfare, nursing facility of elderly health service as well as medical care and treatment facilities that belong to specialized hospitals for the elderly. All these facilities ensure that the old may enjoy perfect nursing service and receive proper rehabilitation from different levels [12].

\subsection{Diversified Organizational Forms That Non-Profit Organizations Participate in Nursing Services}

Diversified organizational forms that non-profit organizations participate in nursing services can be classified as the following four cases in Japan: 1) Government-led organization which is mainly composed of government personnel and civil administrators. 2) Government-funded civil society organizations such as: social welfare association, social welfare trading company and social welfare corporation, etc. 3) Volunteer organizations that mainly include housewives who have received certain training, college students and other groups. 4) Pension service organizations with enterprise type, and the main method is that the enterprises charge a certain amount of insurance and then provide low-cost and high-quality services for the old [13]. All the organizational forms include governmental nature and non-governmental nature, the pay forms include free and charge, and the service personnel include professional and amateur. Diversified forms of home care service not only absorb a growing number of social forces, but also develop home care service into a social career.

Cooperated with the nursing care system, Japan also carried out "Service System for Community Comprehensive Nursing" and "30 Minutes Nursing Community". All these aim at providing small nursing care facilities foe the communities which are 30 minutes away, promoting small-scale and multi-functional home care service and then build new service communities. In addition, neighbors mutual aid career that provides home care service for those difficult elderly people nearby is also the reflection of "Service System for Community Comprehensive Nursing". What's more, students within the community may also provide voluntary services for the elderly in holidays [14].

\subsection{Professional Service Personnel of Non-Profit Organizations Guarantee the Quality of Home Care Service}

For the training of professional social welfare personnel, Japan began to expand relevant educational institutions and developed a unified national examination 
system in the late 1980s and early 1990s. All the personnel that engaged in social welfare must attend and pass this unified national qualification examination and acquired a certificate issued by the state. Otherwise, they were forbidden to participate in welfare work [3]. While most members of non-profit organizations all need to pass these training or obtain relevant qualifications to participate in home care service.

In addition, Japanese government formulated "Law of Social Personnel and Nursing Personnel" in 1987 and stipulated the professional knowledge, technology as well as the work ability they must master, it also introduced the qualification certificate system. In order to protect the rights and interests of the welfare personnel, "Social Personnel law", "Staff Superannuation Law of Social Welfare Facilities" and "Welfare Personnel Protection Law" were all amended and introduced in 1992. In order to improve the professional accomplishment and quality of Japanese social personnel, especially those who were involved in the service of elderly, Japanese government carried out "Registered Social Personnel Law" in 1998, it required all the undergraduate students who majored in social work that they must complete the assigned courses and pass relevant national examinations [15]. It was because that Japanese government promptly issued these laws and regulations to encourage, discipline and manage social personnel, the quality of its non-profit organization members could be improved. As a result, they could provide better and more specialized home care service for the elderly. Meanwhile, both the elderly and social ordinary people were increasingly satisfied and trust non-profit organizations.

\section{Obstruction and Insufficient of the Participation of Domestic Non-Profit Organizations in Home Care Service}

\subsection{Lack of Credibility}

Current credibility of Chinese non-profit organizations is indeed insufficient because of multiple reasons, and this is really a serious impediment for nonprofit organizations to participate in home care service. Development of nonprofit organizations must rely on public trust because credibility is the foundation of its existence and has a direct influence on the social resources they obtain. If there is a lack of credibility, loss of volunteers, reduction of social resources, decreased activity participation and many other issues will appear [16]. In addition, improper financing, corruption and relevant illegal phenomena do exist in non-profit organizations because of the poor oversight, some of them even conduct for-profit activities, all these dishonesty events we mention above have damaged the social image of Chinese non-profit organizations [17]. While these phenomena will directly reduce the trust degree of home care service conducted by non-profit organizations as well as the willingness they participate in home care service.

\subsection{Excessive Government Leading}

Independence is one of the basic characteristics of non-profit organizations 
which refers that they are not subject to government domination and can independently accomplish their missions. While because of the excessive interference of government authorities, current domestic non-profit organizations have too many administrative means, color of internal bureaucracy is increasingly strong and the identity of ordinary people is lacking [18]. Based on the above factors, phenomenon of excessive government management and control really exists in domestic home care service. For example: if a non-profit organization plan to carry out home care and relevant services, it has to pass through layers of approval of government departments. Otherwise, it is difficult to enter the communities and provide services for the old. This indicates that the government still has a strong administrative color in home care service and it fails to appropriately delegate authority to communities as well as non-profit organizations. As a result, both non-profit organizations and communities can neither escape government control nor conduct barrier-free cooperation, and the efficiency and quality of services will certainly decrease.

\subsection{Unprofessional Service Personnel}

Non-profit organizations always emphasize voluntary service, and they are also unable to provide competitive remuneration because of the shortage of funds, they are lack of attractiveness to professionals. As a result, personnel who provide home care service in non-profit organizations are mostly amateur. Although the number of participants reaches the expected demand, both service level and quality decline. Therefore, credibility of non-profit organizations is affected which results in the reduction of social donations [19]. The elderly belongs to a special social group, they need to be loved and taken care of and different elderly people have different needs. So, non-profit organizations should absorb professionals from sociology, psychology, medicine and many other respects to improve the quality of home care service when recruiting.

\section{Implications on Domestic Non-Profit Organizations of Japanese Home Care Service}

From the above discussion, we can see that there are still many shortcomings for the participation of domestic non-profit organizations in home care service. Wherein, both objective reasons like social system and government management as well as subjective reason, lack of development of non-profit organizations are involved. While Japanese successful experience in home care service also has an important implication on the participation of Chinese non-profit organizations in home care service.

\subsection{Perfect Law and System and Establish Supervision Mechanism}

Compared with Japan, there are still many gaps in home care service for the old and the most important is the lacking of perfect legal and system. We have not established a perfect legal system for the participation of non-profit organiza- 
tions in home care service like Japan. As a result, our non-profit organizations confront many obstacles when conducting home care service, and the old are not satisfied and some of them are even feel resentment for such service. We should also draw on Japan to formulate pension service strategy, regard home care service as an important national policy, and formulate appropriate laws and regulations as well as relevant system for home care service, especially the laws aiming at the participation of non-profit organizations in home care service, and then form a complete system. These not only allow the elderly who are comply with the conditions of pension enjoy care service in accordance with law, but also the non-profit organizations may provide home care service more convenient and smoothly. As a result, members of non-profit organizations can be protected by law when providing home care service. In addition, they can also provide high quality services under legal constraints.

China needs to establish an appropriate monitoring mechanism to not only supervise the home service performance of service personnel in non-profit organizations, but also supervise whether the stakeholders behind corrupt or deduct the activity funds of non-profit organizations. To establish a monitoring mechanism can promote the smooth participation of non-profit organizations in home care service as well as community cooperation. For the government, although it needs to intervene, it should also fulfill its own functions like relevant policy development, activity supervision, coordination and personnel management of home care service. Only in this way, public confidence in non-profit organizations will gradually increase.

\subsection{Provide Various Home Care Service}

Before providing home care service for the elderly, both non-profit organizations and families need to take several effective communications with them, and then understand their ideas and demands for home care services. Under the premise of respecting and understanding, they have to consult service contents and then provide tailor-made services for the elderly, especially these who have special demands. In addition, they also need to improve their satisfaction with the home care service provided by non-profit organizations when improving the quality of service.

Our non-profit organizations may also classify both the elderly and volunteers like Japan. For example: the elderly can be distinguished in terms of age, health level and family members, while volunteers can be distinguished in terms of age and service experience. As a result, volunteers who have different experiences might provide more detailed services for the elderly who have different demands. Meanwhile, if conditions permit, non-profit organizations can also cooperate with public welfare medical companies, provide free and simple regular physical examination, psychological counseling and other services for the elderly to obtain a deeper trust.

In addition, responsible person of non-profit organizations may ask their experience and feelings after service, and then they can conduct effective adjust- 
ments and changes to improve service quality. Based on consensual, non-profit organizations can cooperate with domestic service companies to provide paid services for these who have special demands.

\subsection{Improve the Ability of Providing Home Care Service of Non-Profit Organizations}

Apart from these, human resource is really a very important part in non-profit organizations. Wherein, both management personnel and volunteers are the backbone. Because of the particularity of home care clients, groups that provide services need to acquire appropriate service skills and techniques to meet the different demands of different elderly and then enhance their satisfaction. As a result, management personnel and volunteers must go through rigorous and comprehensive training. We may hire Japanese professionals to train our management personnel and volunteers, or we may also dispatch the personal of non-profit organizations to study in Japan. Meanwhile, non-profit organizations and volunteers may develop appropriate reward system through negotiation. For example: they may improve the enthusiasm of volunteers through economic incentives, spiritual incentives and many other means.

\subsection{Enhance the Cooperation between Non-Profit Organizations and Various Organization Departments}

Home care service involves not only non-profit organizations, but also some government organizations and community organizations, and all these organizations are formed by different departments. Therefore, coordinating the cooperation between these organizations as well as internal division of labor within each organizations help improve the service quality and efficiency of non-profit organizations. For example: our country can encourage public investment officers to invest home care service, both the government and media may help nonprofit organizations to complete advanced publicity work, medical and health organizations may provide corresponding medical support, and major colleges and universities may set up relevant courses or subjects about home care service to encourage students to engage in this service. On the basis that non-profit organizations are involved in home care service, we learn from the successful experience of Japan and sum up the roles and division of responsibility of the government, non-profit organizations, community as well as society. Finally, based on concerning about diverse demands of the elderly, we can provide more care and higher quality home care service for them through government guidance, active participation of non-profit organizations.

\section{Conclusions and Deficiency}

Our non-profit organizations have been actively involved in home care service at present, but there are still many problems like insufficient credibility of nonprofit organizations, excessive government-led and unprofessional service personnel. While after years of exploration and practice, Japan has formed a rela- 
tively complete system of home care service. For example: it developed a detailed development strategy, improved relevant laws for the participation of non-profit organizations in home care service, implemented nursing care insurance system and cultivated the volunteers pertinently. We may learn from Japan appropriately, focus on reforms in law formulation, improvement of the non-profit organizations, personnel training and relevant aspects through combining with our own national conditions. Then we can support the participation of nonprofit organizations in home care service progressively and enhance the level of home care service to deal with the problem of aging in China.

Due to the limitation of the ability, reference materials and space, this paper does not make enough use of the successful experience for the old service of Japan's non-profit organizations. The analysis of the status quo of the non-profit organizations participating in the home care service in our country is not comprehensive enough. The discussion in the end of this article is also relatively simple. Thus, in order to get more realistic research, in the future study, we will further tap the material, and make deep analysis of the non-profit organizations participating in home care services.

\section{References}

[1] Wu, D. (2015) Non-Profit Organizations in Home Care Service: Japanese Experience and Revelation for China. Hubei Administration Institute, 1, 43-47.

[2] Qi, F. (2010) Development and Inspiration of Japanese Home Care Service. Northeast Asia Forum, 7, 81-89.

[3] Zhou, D.D., Zhou, H. and Ma, L.Y. (2013) Implications on Domestic Non-Profit Organizations of Japanese Home Care Service. Management Observation, 6, 6-7.

[4] Savas, E.S. (2001) Privatization and Public-Private Partnership. China Renmin University Press, Beijing.

[5] Hong, Y. (2009) Research and Practice of "Government Procurement of Services"Thinking about the Government Purchase of Home Care Service in Ningbo Haishu District. Hunan Tides, 4, 15-16.

[6] Yan, D.B. (2008) Reference of Japanese Community Pension Service System. Reform and Opening, 8, 26-27.

[7] Yin, H. (2012) Population Aging and Aging Strategies of China, Japan and South Korea. International Social Studies, 2, 57-64.

[8] Jin, A.Q. and Sun, J.H. (2012) Participation of Non-Profit Organizations in Home Care Service-Japanese Experience and Revelation. West Anhui University, 6, 1013.

[9] Yoshihiro, I. (2010) Consideration about the Long-Term Care Insurance. http://www.isdi.or.jp/-y-ide/96lkaigo.html

[10] Xie, H. (2011) Revelation of Japanese Geriatric Nursing Development and Personnel Training for China. Chinese Nursing Management, 4, 13-15.

[11] Zhou, Q. (2007) Summary of the Developmental History of Non-Profit Organizations in Japan. Association, 3, 13-17.

[12] Liang, Y. (2012) Development of Japanese Nursing Care Insurance and Its Implications for China. Hebei Law Science, 8, 160-166.

[13] Gong, L.M. (2004) The Community Service for the Aged: The Experience and Re- 
velation of Japan. Urban Management, 6, 38-39.

[14] Chen, J. (2008) The Network of Neighboring Help and the Senior Care in Current Japan. Central University for Nationalities, 5, 106-109.

[15] Lv, X.J. (2007) Japanese Social Welfare and Training for Social Welfare Personnel. Social Welfare, 11, 55-56.

[16] Zhu, S.Y. (2012) Feasibility Analysis on the Participation of Non-Profit Organizations in Community Pension. Social Observatory, 26, 275-276.

[17] Liu, W. (2013) Performance and Countermeasures of Credibility Absence of NonProfit Organizations. Theory Observation, 11, 71-73.

[18] Liu, J.J. and Zhang, B.M. (2008) Non-Profit Organizations and Community Development. Legal and Economic, 8, 98-100.

[19] Fang, J. (2007) Research on Urban Non-profit Organizations under Governance Theory. Ph.D. Thesis, Shandong University, Jinan.

Submit or recommend next manuscript to OALib Journal and we will provide best service for you:

- Publication frequency: Monthly

- 9 subject areas of science, technology and medicine

- Fair and rigorous peer-review system

- Fast publication process

- Article promotion in various social networking sites (LinkedIn, Facebook, Twitter, etc.)

- Maximum dissemination of your research work

Submit Your Paper Online: Click Here to Submit

Or Contact service@oalib.com 